\title{
XXIV. On coal-gas
}

Thomas Thomson M.D. F.R.S. L. and E. M.R.I.A.

To cite this article: Thomas Thomson M.D. F.R.S. L. and E. M.R.I.A. (1844) XXIV. On coal-gas, Philosophical Magazine Series 3, 25:165, 161-169, DOI: 10.1080/14786444408644962

To link to this article: http://dx.doi.org/10.1080/14786444408644962

册 Published online: 30 Apr 2009.

Submit your article to this journal

Џ Article views: 2

Q View related articles $₫$ 


\section{A N D \\ JOURNAL OF SCIENCE.}

\section{[THIRD SERIES.]}

\section{$S E P T E M B E R \quad 184.4$}

XXIV. On Coal-Gas. By 'Thomas Thomson, M.D., F.R.S. L. and E., M.R.I.A., Regius Professor of Chemistry in the University of Glasgow*.

$\mathrm{T} \mathrm{T}$ is well known that the word gas was first introduced into 1 chemistry by Van Helmont in his Treatise de Flatibus. Junker, whose Conspectus Chemice Theoretico Practice was published in 1744, conjectures that Van Helmont's word gas was merely the German word gäscht, fermentation, in a Latin dress, and this conjecture seems as probable as any.

Boyle was the first chemist who attempted to make gas artificially, and who showed that thus prepared it possessed the mechanical properties of common air. The gas which he examined was hydrogen, obtained by pouring dilute sulphuric acid on iron filings.

Hales, in 1726 , proved by experiment that many animal and vegetable substances, when heated sufficiently, give out an air which possesses the mechanical properties of common air, and which therefore he considered as not differing in its properties from common air. That hydrogen gas was combustible was known at least as early as the beginning of the last century, and many remarkable stories are told by early chemists of the eighteenth century, about its combustibility, and the violent explosions which a mixture of it and common air produced when brought in contact with a burning body.

Dr. Black first showed that carbonic acid, though a gas, differed essentially from common air, and he gave it the name of fxed air, because it existed in a solid state in the carbonates. Cavendish, in 1766, showed that hydrogen differs from common air and from carbonic acid; he examined its combustibility, its specific gravity, and pointed out its peculiarities. In 1772 Dr. Priestley began his experiments on air; first he exa-

* Read before the Philosophical Society of Glasgow, November 1, 1843; and communicated to this Journal by the author.

Phil. Mag. S. 3. Vol. 25. No. 165, Sept. 1844. 
mined carbonic acid and hydrogen, then azotic gas, then deutoxide of azote, muriatic acid gas and ammoniacal gas. In 1774 he discovered sulphurous acid gas, and oxygen gas, which was destined to make such an alteration in the chemical theories of the time. He discovered fluoric acid gas and carbonic oxide, though he was not aware of its peculiar nature, and indeed remained ignorant of it to the end of his life.

It is curious that Dr. Priestley nowhere, so far as I know, mentions carburetted hydrogen or heavy inflammable air, as it was then called. It constitutes the fire damp of coal mines; its combustibility and its property of exploding with great violence in certain circumstances must have been known in coal countries at a pretty early period. In the Philosophical Transactions for 1667 , there is an account of a blower of this gas passing through and taking fire from the flame of a candle, and burning briskly; and in the same work there are many histories of explosions in coal mines attended with the loss of many lives.

Though carburetted hydrogen occurs so commonly in coal mines, and though it burns with a strong flame and gives out a good deal of light, and although it had been ascertained that when common coal was distilled at a red heat it gave out a great deal of inflammable gas, it does not seem to have occurred to any person to employ it as a substitute for candles, till the idea struck Mr. Murdoch, an Ayrshire gentleman in the employ of Watt and Boulton. In the year 1808 he published a paper in the Philosophical Transactions, pointing out the advantages that would result from employing conl-gas instead of oil for illuminating the streets of towns and manufactories*.

In this paper he gives an account of the apparatus which he had fitted up for lighting the cotton manufactory of Messrs. Phillips and Lee at Manchester, which was at that time the greatest cotton mill in the kingdom. He shows that the expense was only about one-fourth of that of the candles or oil necessary to produce the same quantity of light that the gas did. The coal used was the best Wigan cannel, a ton of which he says yields 7160 cubic feet of gas, and produces about twothirds of a ton of coke.

In this interesting paper Mr. Murdoch gives the history of the discovery of gas making. In the year 1792, while at Redruth in Cornwall, he made a set of experiments on the quantity and qualities of the gases produced by distillation from different mineral and vegetable substances. He was induced by some observations which he had previously made on the

* [Mr. Murdoch's paper was reprinted in Phil. Mag. S. 1. vol. xxxii,, p. 113.-EDrT.] 
burning of coal to try the combustible properties of the gases produced from it, as well as from peat, wood and other inflammable substances; and being struck with the great quantities of gas which they afforded, as well as with the brilliancy of the light and the facility of its production, he instituted several experiments with a view of ascertaining the cost at which it might be obtained, compared with that of an equal quantity of light yielded by oils or tallow.

In the year 1798 he removed from Cornwall to Boulton and Watt's works at Soho, and there he constructed an apparatus upon a larger scale, which during many successive nights was applied to the lighting of their principal building; and various new modes were tried for washing and purifying the gas. These experiments were continued with some interruptions till the peace of 1802 , when a public display of the gas-light was made by him in the illumination of the manufactory at Soho on that occasion.

Since that period, or between it and 1808 , he extended the apparatus at Soho, so as to give light to all the principal shops, where it was in regular use to the exclusion of other artificial light. In 1808 he fitted up the gas apparatus in Messrs. Phillips and Lee's cotton mill, since which time it has been extended to all the cotton mills in the kingdom.

I have stated these details, though but imperfectly connected with the subject which I mean to discuss, because I believe the history of the introduction of gas as a substitute for oil or candles is not very generally known. It is commonly ascribed to Mr. Windsor, who took out a patent in 1806 and who delivered lectures on the subject several years after, and who endeavoured to get up a joint stock company, with what success I do not know. Several attempts were made here about the year 1808, and during the winter of that year the front of the Tontine buildings at the Cross of Glasgow was lighted with gas for several weeks. London was the first city illuminated with gas. Philip Taylor erected the gas-works at Paris soon after the peace of 1815 .

In the preceding historical sketch $I$ have taken no notice of Lord Dundonald's coal-tar works at Culross; the current of gas escaping from his ovens was frequently fired; but it does not seem to have occurred to him to employ the gas thus extricated for cconomical purposes. Nor have I noticed M. Lebon, who is said in 1786 to have attempted, but without success, to employ gas distilled from wood as a substitute for candles; these attempts led to no results and were speedily forgotten.

There are four varieties of coal which have been tried in Great Britain in the manufacture of gas, namely, caking coal, 
cherry coal, splint coal and cannel coal. Of these the cannel coal, or parrot coal as it is called here, yields the best gas; the caking coal, or Newcastle coal, yields the worst, and the cherry and splint, though very different in their appearance, yield an intermediate gas, the quality of which, whether from cherry or splint coal, is nearly the same.

There are three varieties of cannel coal in the neighbourhood of Glasgow, named from the localities where they occur, Skaterigg, Lesmahagow and Monkland.

The specific gravity of these varieties of coal is as follows:Caking coal . . 1.280 Mr. Richardson.

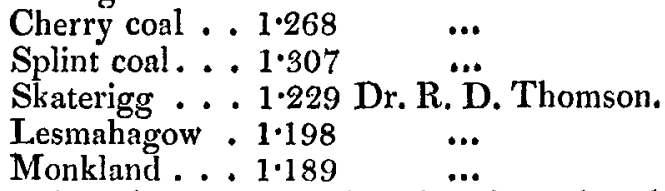

Besides ashes, these six varieties of coal consist of carbon, hydrogen, azote and oxygen, combined in various proportions according to the coal. I shall here give the composition of each; that of the first three was determined by Mr. Richardson of Newcastle in the laboratory at Giessen; that of the last three in the College laboratory by Dr. R. D. Thomson. The azote is small in quantity, so small that $\mathrm{Mr}$. Richardson did not succeed in determining its exact quantity; but we found no difficulty in coming to very exact conclusions by the process of Will and Varrentrapp*. As the quantity in all our varieties tried varied from $1 \cdot 48$ to 1.75 per cent., I have supposed that the azote in the three varieties determined by $\mathrm{Mr}$. Richardson was the mean of these two quantities, or 1.61 per cent. The following table shows the composition of these coals :

Mr. Richardson.

\begin{tabular}{|c|c|c|c|c|c|c|}
\hline \multirow[b]{3}{*}{ irbon } & & \\
\hline & Caking & Cherry & Spm & Skateri & Lesmahagow & Monkland \\
\hline & $87 \cdot 952$ & $\begin{array}{c}\text { coal. } \\
83 \cdot 025\end{array}$ & $\begin{array}{c}\text { coal. } \\
82 \cdot 924\end{array}$ & $\begin{array}{c}\text { coal. } \\
76^{-20}\end{array}$ & coal. & $\begin{array}{c}\text { coal. } \\
70 \cdot 02\end{array}$ \\
\hline Hydrogen. & 5.239 & $5 \cdot 250$ & $5 \cdot 491$ & $5 \cdot 44$ & 6.07 & 5.56 \\
\hline Azote...... & 1.610 & 1.610 & $1 \cdot 610$ & $1 \cdot 75$ & $1 \cdot 61$ & $1 \cdot 48$ \\
\hline Oxygen ... & $3 \cdot 806$ & $8 \cdot 566$ & $8 \cdot 847$ & $14 \cdot 47$ & $12 \cdot 26$ & $14 \cdot 86$ \\
\hline Ashes.. & $1 \cdot 393$ & $1 \cdot 549$ & $1 \cdot 128$ & $2 \cdot 14$ & $2 \cdot 81$ & $8 \cdot 08$ \\
\hline & 00 & $100^{\circ}$ & $100^{\circ}$ & $100^{\circ}$ & $100^{\circ}$ & $100^{\circ}$ \\
\hline
\end{tabular}

It will facilitate our conception of the composition of these different coals if we exhibit their condition by empirical formulas representing the atoms of each constituent, the quantity of azote being reckoned one atom : we leave out the ashes, because they have nothing to do with the production of the gas, excepting that they materially influence its quantity.

* This process was first proposed by Dr. Schafhaeutl, in Phil. Mag. [S. 3, vol. xvi. p. 44.] 


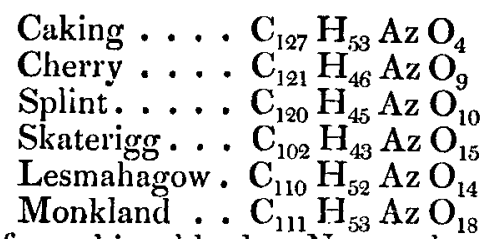

It appears from this table that Newcastle coal contains the most carbon, and Monkland cannel coal the least; while cannel coal contains the most oxygen and Newcastle coal the least; Newcastle coal contains the least hydrogen and cannel coal the most. Now cannel coal yields the best and Newcastle coal the worst gas. This need excite no surprise; carbon not being volatile, it is obvious that if coal contained nothing but carbon it would yield no gas at all. Coal-gas is a mixture of four different gases, most of which are compounds; two are compounds of carbon and hydrogen, one of carbon and oxygen, and the fourth is pure hydrogen. There is no difficulty in conceiving the formation of the gaseous compounds of carbon and hydrogen, but it is not so easy to explain the occurrence of carbonic oxide and hydrogen. These two gases are never entirely wanting; at least I have analysed above forty specimens of coalgas from different kinds of coal and from different gas-works without ever failing to find them. I think it probable that they make their appearance towards the end of the process of heating the coal. It is well known that the longer the process of gas making is continued, and the higher the temperature at which the gas is produced, the worse is the gas, and of course the more hydrogen it contains. Is it not possible that coal may contain water; that this water can only be extricated at a high temperature; that its oxygen combines with carbon and forms carbonic oxide, while the hydrogen makes its escape in the gaseous state? If this supposition were true, there ought to be a constant ratio between the volume of carbonic oxide and hydrogen in the coal-gas; but this not being the case, it is obvious that the supposition cannot be well founded*

* Mr. John Hart, of this city, states that he made an experiment which appears to explain the appearance of the hydrogen towards the end of the process. "Having conceived the idea many years ago of causing gas to take up an additional dose of carbon, by passing it over red-hot charcoal, he procured a $1 \frac{1}{2}$-inch iron pipe, and having charged it with charcoal he passed it through the furnace below the gas retort, and joined one end with the pipe from the retort and the other to the pipe leading to the condenser; the fire was then applied and the retort charged as usual. After the gas-holder had risen about a foot, he observed the lead pipe leading to the condenser becoming very hot; it soon after gave way and fell to pieces, and the whole of the gas escaped into the air; but it had no longer the yellow silky appearance of gas issuing from a retort; it had become a white vapour, and bad also lost the smell. When the charcoal was examined it 
A ton of Lesmahagow coal, when distilled at the usual temperature, yields about ( 10,080 cubic feet) one-fifth of its weight of gas, two-fifths of coke, and two-fifths of tar, water, \&c.

The gas contains about one-fifth of the carbon in the raw coal, two-elevenths of the hydrogen, and two-ninths of the oxygen; about one-half of the carbon remains in the state of coke, so that about two-fifths go to the formation of the naphthalin, naphtha, naphthene, naphthol, \&c., which are formed during the distillation.

Nine-elevenths of the hydrogen and seven-ninths of the oxygen go to the formation of water and various other compounds. The ammonia formed amounts to about 1 per cent. of the liquor obtained during the distillation of the coal.

When gas-works were first established the coal was distilled in iron retorts, but it has been found more œconomical to substitute vessels of stoneware, or rather indeed ovens of firebrick made air-tight; these I believe are generally superseding the iron retorts.

During the course of last winter I made thirty-five analyses of gas from different gas-works, but most commonly Glasgow gas. The gas which I used was taken from a pipe at some distance from the gas-works, because the gas required to be washed and purified before it was examined. After turning the stopcock the gas was kindled and allowed to burn for several minutes before $I$ began to collect it. In every case it contained a mixture of common air, which varied in different specimens of gas from 4 per cent. to 28 per cent.; the mean quantity was $12 \frac{1}{2}$ per cent. The specimen containing 28 per cent. of common air was brought up from Greenock, and though very great care was taken in packing it, it is possible that at least a portion of this air might have made its way into the bottles during the transit. If we omit this specimen, the average quantity of common air in the Greenock gas was $10 \frac{1}{2}$ per cent; the average quantity in the Glasgow gas was $12 \frac{1}{3}$ per cent.

I think it most likely that the common air, which forms a constant ingredient in all gas from gas-works that $I$ have examined, had made its way into the pipes, which it must be very difficult to make air-tight; and when the pressure is removed common air will undoubtedly enter wherever it can find access. The Greenock gas was collected in an apartment very near the gas-works; the Glasgow gas was collected

was found to be covered over witl a fine smooth, shining black coat of carbon, which had been deposited on it." Mr. Hart has concluded from this and other facts, that the gas is decomposed by the red-hot coke, and proposes that the coal should be applied in thin layers to the interior surface of the retorts. 
in my laboratory, which may be about a furlong from the gasworks; now the average quantity in the Greenock gas was $10 \frac{1}{2}$, and in the Glasgow $12 \frac{1}{3}$.

The highest specific gravity of the Glasgow gas was 0.582 , and the lowest 0.463 ; the average was 0.502 .

The quantity of olefiant gas in Glasgow gas varied from 11.77 per cent. to 17.83 per cent; the mean quantity was 13.52 per cent.

I got gas made at Greenock with as much care as possible from each of the three varieties of cannel coal found in the neighbourhood of Glasgow, namely Skaterigg, Lesmahagow and Monkland: the specific gravities of these gases were,

Skaterigg . 0 0.497

Lesmahagow 0.560

Monkland . . 0.622

The olefiant gas per cent. contained in each was as follows :-

Glasgow . . 13.52

Skaterigg . . 14:15

Lesmahagow. $16^{\cdot} 66$

Monkland . . 22:15

Mr. Ritchie, the manager of the Greenock gas-works, who prepared these gases, told me that he thought rather too much heat had been applied to the Lesmahagow coal, which in his opinion would have somewhat deteriorated the Lesmahagow coal-gas.

The mean quantity of carburetted hydrogen gas in the Glasgow coal-gas was $60 \cdot 6$ per cent; the smallest quantity was $47 \cdot 33$, and the largest $79 \cdot 77:$ the quantity of this gas in the gases from cannel coal was as follows:-

Skaterigg . . 66.49

Lesmahagow. 59.94

Monkland . . 48.77

The goodness of these gases is in the order of naming them. It would appear from this, that the smaller the proportion of carburetted hydrogen the better is the gas; the reason is that the olefiant gas increases as the carburetted hydrogen diminishes.

The average quantity of carbonic oxide in Glasgow gas was 12 per cent., the smallest quantity was 6.34 per cent., and the greatest quantity 15 per cent.: the quantity of this gas in the three gases fronı cannel coal was as follows:-

Skaterigg . . 7.07

Lesmahagow. 12.00

Monkland . . 11.76

The mean quantity of hydrogen gas in Glasgow gas was $12 \cdot 4 \cdot 4$ per cent., the greatest quantity was $22 \cdot 85$ per cent., and the 
smallest quantity $2 \cdot 21$ per cent: the quantity in the three gases fiom cannel coal was as follows:-

$$
\begin{aligned}
& \text { Skaterigg . . 12.29 } \\
& \text { Lesmahagow. 11.46 } \\
& \text { Monkland . . 17.32 }
\end{aligned}
$$

The common method of determining the light emitted by gas during its combustion, is to set fire to a jet of a given height and issuing from an orifice of a given diameter, and to compare it with the light given out by a wax candle of six in the pound, usually denominated short sixes; an opake body is placed on a sheet of paper, horizontally between the two flames, and it is so placed that the two shadows formed by it are of equal intensity. The distance between this opake body and the flames is measured, and the light emitted by each is as the square of that distance; thus, if the distance between the gas flame and the opake body be two feet, while its distance from the flame of the candle is only one foot, then the light given out by the gas is four times as great as that of the candle.

The light given by the combustion of a jet of Glasgow gas, issuing from an orifice of $\frac{1}{30}$ th of an inch in diameter and four inches in height, was as follows:-

1. On the north side of the river $=2 \cdot 68$ candles.

2. On the south side of the river $1.77 \quad \ldots$

This method of measuring the quantity of light appears at first sight very simple, but I found on trial that it was attended with so many sources of error that I was afraid to depend upon it. Fortunately there is another method of much easier execution, which I found much more satisfactory.

The quantity of light given out during the combustion of coal-gas is very nearly proportional to its specific gravity; the heavier a gas is the slower does it issue from an orifice of a given diameter when propelled by a given force. I measured the time which a cubic foot of each gas took to issue from an orifice of $\frac{1}{50}$ th of an inch, when propelled by a force such as to form a jet of flame, when lighted, of four inches in length, and I considered the goodness of the gas as proportional to this time: the result was as follows:-

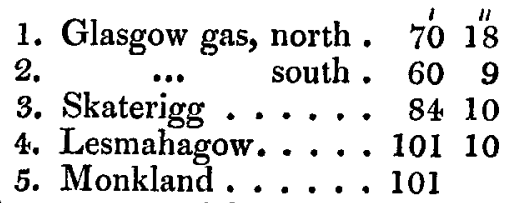

Certainly, in a commercial point of view, the value of the gas (the price per cubic foot being the same in all) is exactly 
proportional to the time that it takes to burn, because the consumption in a given time depends upon that time.

If, therefore, a thousand cubic feet of gas be charged $8 s$. on both sides of the river, it is clear that the consumers on the south side pay at the rate of $9 s$. $4 d$. per cubic foot, because they consume 7000 cubic feet in the same time that those on the north side consume 6000 .

If Glasgow gas, Skaterigg gas and Lesmahagow gas are each charged at $8 s$. per 1000 cubic feet, the price paid by the consumers will be

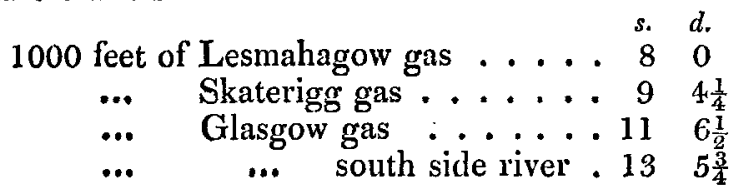

XXV. Note on the Decomposition of Carbonic Acid by the leaves of Plants under the infuence of Yellow Light. By John William Draper, M.D., Professor of Chemistry in the University of Nere York.

I $N$ the year 1836 I discovered that the leaves of plants possess the quality of effecting the decomposition of carbonic acid under the influence of light which had passed through a solution of bichromate of potash, and which was so completely detithonized as to be unable to darken the chloride of silver. Under the same circumstances also, young plants which had been etiolated by germinating and growing in the dark, turned green in a few hours by the fixation of carbon, so as to constitute chlorophyll. Seeds also appeared to germinate without any difficulty, and eventually produced vigorous green plants.

These results were published in 1837 in the Journal of the Franklin Institute of Philadelphia * I have likewise referred to them in the Phil. Mag. (Feb. 1840).

From time to time Mr. Hunt of Falmouth has called the accuracy of these experiments in question, and having made some investigations under the direction of the British Association, at its expense, he has published reports on the matter. It is the object of these publications to substantiate a doctrine which is derived from Sennebier, that the blue and violet chemical rays are the true cause of the decomposition.

That there might remain no reasonable doubt of the correctness of the views I had given, I repeated the experiment of

* I will take this opportunity to state that the experiments here alluded to, with some others, are now collected together, and are in the press. They will be in the hands of the English reader in a few weeks. 